\title{
Gender differences in social interactions of children: A naturalistic approach
}

\author{
J. MARTIN RAMIREZ and DIANA L. MENDOZA \\ Seville University, Seville, Spain, and Center Ramon y Cajal, Madrid, Spain
}

\begin{abstract}
Differences in the social behavior of 6- and 7-year-old children of both sexes were analyzed by ethological methods. Observations were made while children attended class in a regular firstgrade school. The incidence of general activity, social interaction, and open hostile activity was higher in boys. No significant differences between sexes were observed in cohesive, ambivalent, and flight components of behavior. Children of both sexes interacted more with girls. These results seem to indicate that gender differences in the way children interact with their peers are more evident during aggressive encounters and that they depend not only upon the sex of the actor, but also upon the sex of the receiver.
\end{abstract}

Research on sex-related issues has hardly been quiescent during the past years. Considerable activity has led to genuine insight into the influence of sex as a subject variable, the contribution of individual different traits, and the pervasiveness of gender stereotypes (Deaux, 1984). What are the main gender differences in behavior, if any, and when do they appear in the ontogenetic development of human beings? After reviewing more than 1,400 published studies, Maccoby and Jacklin (1974) concluded that very few sex differences have been substantiated. Their conclusions, however, have been challenged by other authors (such as Block, 1976).

Although numerous situational factors appear to elicit or minimize gender differences (Frodi, Macaulay, \& Thome, 1977), sex-related phenomena cannot be qualified merely by "'molding"' situational pressures. They are also influenced by individual biological constraints and by personal choices based on past interactions and future expectations (Hinde, 1982, 1984; Hinde \& StevensonHinde, 1976; Mendoza \& Ramirez, in press; Ramirez, $1978,1984)$, and ultimately they are understandable only if analyzed in the context of social interaction (Dunn, 1976). As Hinde (1982, 1984; Hinde, Easton, Meller, \& Tamplin, 1983) pointed out, individuals behave differently according to where they are (social situation), whom they are with (presence of adults, and even of different kinds of peers), and their own individual characteristics and cultural backgrounds (social class, ethnic group values and norms, and expectations). In sum, human relationships vary in a complex way.

Social interaction could be assessed in a variety of ways, such as by reports, verbal interviews or questionnaires, and direct observations of behavior. Verbal interviews alone provide a relatively poor index, especially at early

Both authors are affiliated with the Department of Psychology, Seville University, Seville, Spain, and with the Research Department, Center Ramon y Cajal, Madrid, Spain. Requests for reprints should be directed to: J. M. Ramirez, Psychobiology, Universidad de Sevilla, Sevilla, Spain. ages, and laboratory observations of a selected subject population are not exempt from constraints and pressures; for instance, as Eagly (1983) observed, these experimental situations may emphasize the subject role to the exclusion of more complex sex-related roles that may be prevalent in the field, and may even put more stress on what a subject can do than on what he or she will do, given free choice, in a more natural environment. Therefore, the essence of ethological research must be to observe, to note, to question, and to postulate particular phenomena first in the real world, that is, individuals' interactions within a naturalistic setting. Only after we have gotten a clear picture of what has occurred there-and only as needed-can we utilize experimental settings (Omark, 1980). The advantage of recording behavioral interaction in a context appropriate to the situation in which it occurs (Attili, 1984) does not mean that human ethologists should restrict themselves to naturalistic observations; on the contrary, since all scientific disciplines are defined by multiple methodologies, we should complement them with the other means at our disposal.

This paper will consider sex-of-subject behavioral differences through the traditional approach of considering sex as a subject variable. Our present effort is limited to: (1) discussing some of the methodological procedures involved in ethological observations of spontaneous behavior among children in a natural school setting; and (2) analyzing their nature, that is, what they were doing together (content), degree of interaction (frequency), and who did what to whom (directionality).

\section{METHOD}

\section{Subjects}

The sample consisted of 34 "nonproblem" children of both sexes (17 boys and 17 girls), between 6 and 7 years old, and attending a regular first-grade public school in an industrial area of Madrid. Socio-economic level and occupation of parents indicated that they belonged to the lower middle class. 


\section{Procedure}

Since behavior may vary throughout the day and even the week, and may depend on the weather, among other biorhythmical and environmental circumstances, observations were conducted in a classroom on consecutive weekdays, at three different times of the day (early morning, late morning, and afternoon) over a period of 1 month, during the spring.

In order to get more complete information about the observed population, two matrix completion sampling methods previously used by other researchers (Altman, 1974; Behoff, 1979; Blurton-Jones, 1972; McGrew, 1972; Michael \& Crook, 1973) were applied: (1) individual focal sampling, that is, recording all the specific behaviors of each individual, and (2) event sampling, that is, recording the frequency of the different behavioral patterns in a population without taking into account the performer.

During previous field observations of nonhuman and human primates (Mendoza, 1982; Mendoza \& Ramirez, 1984, in press), a coding system was developed and a repertoire of 47 specific categories that described various behavioral events was selected as a checklist for the current research and grouped under five headings: (1) "neutral"approach, move away, verbalize, vocalize, walk, jump, run; (2) "ambivalent"- yawn, rock, touch, digit or object suck, rough-andtumble, chew lips; (3) "hostile"'-frown, interfere, displace, tongue showing, point at, restrain, object struggle and break, scream, pinch, bite, intentional hit, hit, punch, step, kick, push and pull, wrestle, chase; (4) "flight"-crouch, flinch, flee, pout, cry; and (5) "cohesive-smile, laugh, hug, pat. Most of these behavioral events had been defined elsewhere (Blurton-Jones, 1972; McGrew, 1972). The behaviors exhibited were coded according to a previously developed system, recording the actor and the target of each interaction as well as their sex.

At the inception of the project, two arbitrary decisions were made: (1) to use a unit of analysis, that is, the sampling period for each focal individuum (Altman, 1974), of $1 \mathrm{~min}$; and (2) to consider a minimum sampling of $60 \mathrm{~min}$ of observational recording of each subject as a baseline measure sufficient for a stable estimate of behavioral events. A total of 1,782 min of videotaped social interaction were obtained during the period of study: Of this total, 926 min were of male actors and $856 \mathrm{~min}$ of female ones. The observation of the different subjects was done in random order. During recording of the data, each child sat in the classroom between two other children of the opposite sex. For easier identification of the focal individuum, each subject was assigned a fixed number, which was placed on his/her front and back.

\section{Observers}

Observations were performed by two persons through a one-way mirror (to keep the observers out of the view of the children). Each observer was equipped with a recording keyboard and audiophones with a chronometric device for timing the 1-min intervals.

Training in the use of the code system required approximately $15 \mathrm{~h}$ and involved practice sessions of viewing and coding videotapes of social interaction. After that, the person being trained attended the school with an experienced observer; both of them coded the behavior observed in the children. Training continued until they had reached a minimum agreement of $75 \%$. The overall percentage of agreement was calculated by summing the events observed for all children in a session for both observers and dividing that into the total number of events for which they were in agreement (Patterson \& Cobb, 1973). During sessions, an interobserver agreement of around $85 \%$ was obtained.

During the few contacts of the observers with the children, no services were offered and no conversation was exchanged with the children. The first several days of observation at the school were spent simply looking at the behavior of the children and sham-recording. This was done not only for technical reasons, but also to habituate the children to the observers' presence. In fact, after a very few sessions, the children displayed no reactions to the observers' presence: Most of them merely glanced in the observers' direction upon entrance. Therefore, no distortion was detected in social interactions as a function of the observers' presence at the school.

\section{Data Analysis}

To avoid any distortion in the data, after the field observations were collected the videotapes were rerun until all observers agreed in their coding. Only the data for children who were present for at least $75 \%$ of the sampling period were analyzed. The data for the different behavioral categories were subjected to an analysis of variance (ANOVA) for the several sessions, and the frequencies with which each behavior occurred in both groups were subjected to a chi-square analysis, with appropriate correction or Fisher's exact chi-square when required. Chisquare values determined whether the gender differences in a given behavior were significant at $\mathrm{p}<.05$.

Although not included in the present paper, other assessment procedures, such as tests, questionnaires, and several psychophysiological measures were also applied to the children, and there were interviews with their parents and teachers to obtain more complete information on the sociobiopsychological peculiarities of the subjects.

\section{RESULTS}

Absolute frequency of interactions tells us how much social behavior a person shows. When we grouped all the behavioral categories observed by gender, we found that the incidence of social interactions was significantly higher in boys $(84.71 \%$ ) than in girls $(74.30 \%)$, and that both boys and girls tended to direct their behavior more than twice as frequently toward girls $(67.28 \%$ of the total interaction) than toward boys (32.72\%).

What proportion of their interactions at school were hostile? Boys were always more aggressive $(21.12 \%)$ than girls $(14.95 \%)$, and both sexes directed their hostility significantly more often toward girls. The quality of the hostility also differed according to the subject's sex. Physical contact directed toward an opponent or toward a "scapegoat" (redirected aggression) was typical of boys. Girls, on the other hand, made less use of physical con-

Table 1

Sex Directionality for Different Types of Social Interactions in Normal Children

\begin{tabular}{|c|c|c|c|c|c|c|c|c|c|c|}
\hline \multirow{2}{*}{$\begin{array}{l}\text { Types of } \\
\text { Behavior }\end{array}$} & \multicolumn{2}{|c|}{ Boy to Boy } & \multirow{2}{*}{$\begin{array}{c}\text { Level of } \\
\text { Significance }\end{array}$} & \multicolumn{2}{|c|}{ Boy to Girl } & \multicolumn{2}{|c|}{ Girl to Boy } & \multirow{2}{*}{$\begin{array}{c}\text { Level of } \\
\text { Significance }\end{array}$} & \multicolumn{2}{|c|}{ Girl to Girl } \\
\hline & Raw Score & Percent & & Raw Score & Percent & Raw Score & Percent & & Raw Score & Percent \\
\hline Neutral & 177 & 19.12 & $\mathrm{p}<.01$ & 293 & 31.64 & 108 & 12.62 & $\mathrm{p}<.01$ & 268 & 31.30 \\
\hline Ambivalent & 19 & 2.05 & $\mathrm{p}>.05$ & 30 & 3.24 & 12 & 1.40 & $p>.05$ & 18 & 2.10 \\
\hline Hostile & 30 & 4.10 & $p<.01$ & 158 & 17.06 & 53 & 6.19 & $p<.05$ & 75 & 8.76 \\
\hline Flight & 0 & 0.00 & $\mathrm{p}<.05$ & 6 & 0.44 & 0 & 0.00 & $p<.05$ & 0 & 0.00 \\
\hline Cohesive & 65 & 7.02 & $\mathrm{p}>.05$ & 54 & 5.83 & 48 & 5.61 & $\mathrm{p}>.05$ & 44 & 5.14 \\
\hline Total & 229 & 32.29 & $\mathrm{p}<.01$ & 541 & 58.21 & 231 & 25.82 & $\mathrm{p}<.01$ & 405 & 47.30 \\
\hline
\end{tabular}

Note-Total observations: boys $=926 ;$ girls $=8.56$ 
tact, carrying out their behavior by gestures; furthermore, their hostility was often redirected toward inanimate objects or was expressed by trespassing on the opponent's personal territory.

A series of behaviors bearing a deep social meaning, such as approaching, moving away, and verbalization, were grouped under the label of "neutral" behaviors. Verbalization failed to reveal any difference between boys (24.51\%) and girls (24.65\%). However, boys approached and moved away from their peers approximately one-third more often than girls (boys: $20.09 \%$ and $6.16 \%$; girls: $14.60 \%$ and $4.56 \%$, respectively). In all these cited "neutral" behaviors, the actors, whether boys or girls, preferred to direct their interactions toward girls rather than toward boys $(\mathrm{p}<.001)$.

No significant gender differences were observed either in cohesive behaviors or in ambivalent ones. Flight was practically nonexistent, perhaps partially because observations were made during class hours.

\section{DISCUSSION}

Our current data observed in 6- and 7-year-old schoolchildren support the gender differences in behavior that have been widely reported in a variety of cultural settings. Hinde (1984) observed marked sexrole differences in children between the ages of 42 and 50 months. And Freedman (1980) described subtle differences even at birth: Boys cry more, respond less to vocal cajoling and require more holding, whereas girls start life more cuddly, mold into the arms better, and kick less. The significantly higher overall behavioral activity observed in our sample of boys confirms earlier findings by Draper (1980). He observed that boys physically cover more ground than girls in the same amount of time (i.e., are more active than girls). Our most noticeable result was the social "attractiveness" of girls; that is, children of both sexes preferred to interact with females.

Our analysis demonstrates that boys exhibit a higher rate of hostile behavior. This is in line with most studies on aggressiveness: Boys are more likely to act out aggressive displays, tending to be at the top of a toughness dominance hierarchy (Barrett, 1979; Maccoby \& Jacklin, 1974, 1980; Parker \& Omark, 1980; Strayer \& Strayer, 1980). Crosscultural studies (Freedman, 1974, at 5 to 7 years; Omark, 1980, at 4 to 10 years; Ramirez et al., 1984, at 6-7 years; Whiting \& Pope, 1973, at 2 to 10 years) also have reported gender differences in the physically aggressive behavior of children: Males engaged more in mock fighting, rough play, and verbal insults. Moreover, convincing evidence seems to appear quite early on in ontogenetic development. According to the ethological findings of gender differences in preschool aggressive interactions, males seem to be born with a lower threshold for aggressive responsiveness (Blurton-Jones, 1967; Hinde, 1984; Knudson, 1973; McGrew, 1972).

Our findings diverge from the popular thinking that girls talk more than boys, and from the results of earlier studies showing that girls are more socially oriented right from the start (Freedman, 1980; McGuinness, 1980). The reports by Knudson (1973) and McGrew (1972) on preschoolers' interactions showed typically nonagonistic interactions among females. In these studies, moreover, only male-to-male interactions were unfriendly. Our children, however, did not express significant differences in approach and verbalization, both sexes participating also in hostile interactions. What seems more interesting is that most directed "hostility" toward girls, contradicting Attili and Cavallo-Boggi's (in press) observation of preschoolers that aggressiveness is directed more toward like-sex individuals than toward opposite-sex ones. Although such studies need to be replicated in the future, a possible explanation occurs to us: Both the ages and the social contexts of the subjects varied.
Here we have focused on documenting sex differences in social interactions and have demonstrated, as did Attili (1984), that these differences depend not only upon the sex of the actor but also upon the sex of the receiver. Although we agree with Attili about the importance of examining factors beyond the overall frequencies and asking how the social behavior is affected by a variety of independent variables, because this depends on different motivational factors, we also share Hinde's (1982; Hinde \& Stevenson-Hinde, 1976) hope that a naturalistic approach may stimulate and provide a starting point for the understanding of the social-sexual relationships.

\section{REFERENCES}

Altman, J. (1974). Observational study of behavior: Sampling methods. Behavior, 49, 227-267.

ATTILI, G. (1984). The influence of familiarity and target characteristics on aggression and social skills in preschool children. Manuscript submitted for publication.

Attili, G., \& Cavallo-Boggi, P. (in press). Aggression and social skills in children's relationships: Sex differences. In J. M. Ramirez $\&$ P. F. Brain (Eds.), Aggression: Functions and causes. Seville: Seville University Press.

BARRETT, D. E. (1979). A naturalistic study of sex differences in children's aggression. Merrill-Palmer Quarterly, 25, 193-203.

BeHOFF, M. (1979). Behavioral acts: Description, classification, ethogram analysis and measurement. In M. Behof (Ed.), The analysis of social interactions. Hillsdale, NJ: Erlbaum.

BLOCK, J. H. (1976). Issues, problems, and pitfalls in assessing sex differences: A critical review of the psychology of sex differences. Merrill-Palmer Quarterly, 22, 193-203.

BLuRTON-JoNes, N. G. (1967). An ethological study of some aspects of social behavior in children in nursery school. In D. Morris (Ed.), Primate ethology. London: Weidenfeld and Nicholson.

BLuRTON-Jones, N. G. (1972). Categories of child-child interaction. In N. G. Blurton-Jones (Ed.), Ethological studies of child behavior, London: Cambridge University Press.

DEAUX, K. (1984). From individual differences to social categories: Analysis of a decade's research on gender. American Psychology, 39, 105-116.

DRAPER, P. (1980). The interaction of behavior variables in the development of dominance relations. In D. R. Omark, F. F. Strayer, \& D. G. Freedman (Ed.), Dominance relations (pp. 427-442). New York: Garland STPM Press.

DunN, J. (1976). How far do early differences in mother-child relations affect later development? In P. P. G. Bateson \& R. A. Hinde (Ed.), Growing points in ethology (pp. 481-496). London: Cambridge University Press.

EAGLY, A. (1983). Gender and social influence: A social psychological analysis. American Psychologist, 38, 971-981.

FREEDMAN, D. G. (1974). Human infancy: An evolutionary perspective. Hillsdale, NJ: Erlbaum.

FreEdMAN, D. G. (1980). Sexual dimorphism and the status hierarchy. In D. R. Omark, F. F. Strayer, \& D. G. Freedman (Ed.), Dominance relations. New York: Garland STPM Press.

Frodi, A., Macaulay, J., \& Thome, P. R. (1977). Are women always less aggressive than men? A review of the experimental literature. Psychological Bulletin, 84, 634-660.

HINDE, R. A. (1982). Ethology: Its nature and relations with other sciences. New York: Oxford University Press.

HINDE, R. A. (1984). Home aggression in four-year-old children. Manuscript submitted for publication.

Hinde, R. A., Easton, D. F., Meller, R. E., \& Tampuin, A. (1983). Nature and determinants of preschoolers' differential behavior to adults and peers. British Journal of Developmental Psychology, 1, 3-19.

Hinde, R. A., \& STEVENSON-Hinde, J. (1976). Towards understanding relationships: Dynamic stability. In P. P. G. Bateson \& R. A. Hinde (Ed.), Growing points in ethology (pp. 455-480). London: Cambridge University Press. 
KNuDson, M. E. (1973). Sex differences in dominance behavior of young human primates. Unpublished doctoral dissertation, University of Oregon, Eugene.

Maccoby, E. E., \& JaCKLIN, C. N. (1974). The physiology of sex differences. Stanford, CA: Stanford University Press.

MACCOBY, E. E., \& JACKLIN, C. N. (1980). Sex differences in aggression: A rejoinder and reprise. Child Development, 51, 964-980.

McGrew, W. C. (1972). An ethological study of children's behavior. New York: Academic Press.

McGuINNESS, D. (1980). The nature of aggression and dominance systems. In Absolute values and the search for the peace of mankind (pp. 1091-1107). New York: International Cultural Foundation Press.

Mendoza, D. L. (1982). Organización social de los monos barizo (Saimiri sciuieus). Unpublished doctoral dissertation, Complutense University of Madrid.

MendozA, D. L., \& Ramirez, J. M. (1984). Ethological observations of cohesive and aggressive behavior during class hours. Aggressive Behavior, 10, 162.

Mendoza, D. L., \& Ramirez, J. M. (in press). Aggressive interactions in non-human primates. Some genetical and environmental factors. In D. McGuinness (Ed.), Status and rank: Missing variables in the analysis of war. New York: Paragon Press.

Michael, R., \& Crook, J. (1973). Comparative ecology and behavior of primates. New York: Academic Press.

OMARK, D. R. (1980). Human ethology: A holistic perspective. In D. R.
Omark, F. F. Strayer, \& D. G. Freedman (Ed.), Dominance relations (pp. 3-20). New York: Garland STPM Press.

PARKeR, R., \& OMARK, D. R. (1980). The social ecology of toughness. In D. R. Omark, F. F. Strayer, \& D. G. Freedman (Eds.), Dominance relations (pp. 415-426). New York: Garland STPM Press.

Patterson, G. R., \& CoBb, J. A. (1973). Stimulus control for classes of noxious behaviors. In J. F. Knutson (Ed.), The control of aggression (pp. 145-199). Chicago: Aldine.

Ramirez, J. M. (1978). Einfuhrung in die Anthropobiologie. Bern: Peter Lang.

RAMIREZ, J. M. (1984). Vida, ambiente y biologia. Madrid: Centreur.

Ramirez, J. M., MEndozA, D. L., \& LABORDA, R. (1984). Social behavior of Spanish and Mexican children during play. A cross-cultural study. In Proceedings of the 23rd International Congress of CrossCultural Psychology (Vol. II, p. 169). Acapulco.

Strayer, F. F., \& STrayer, J. (1980). Preschool conflict and the assessment of social dominance. In D. R. Omark, F. F. Strayer, \& D. G. Freedman (Eds.), Dominance relations (pp. 137-158). New York: Garland STPM Press.

Whiting, B. B., \& Pope, C. P. (1973). A cross-cultural analysis of sex differences in the behavior of children aged three through eleven. Journal of Social Psychology, 91, 171-188.

(Manuscript received for publication May 31, 1984.) 